\title{
NEW PROCESS MANAGEMENT FOR EMERGENCY MANAGEMENT: CASE STUDY ABOUT AN ACCIDENT OF A VEHICLE TRANSPORTING DANGEROUS GOODS
}

\author{
Tomáš Ludík, Jaroslav Ráček and Lucie Pekárková \\ Faculty of Informatics \\ Masaryk University \\ Botanická 68a, Brno, Czech Republic \\ E-mail: xludik2@fi.muni.cz, racek@fi.muni.cz, pekarkova@fi.muni.cz
}

\begin{abstract}
KEYWORDS
Emergency Management, Process Management, Process Framework for Emergency Management, Verification and Validation, Optimization, Case Study.
\end{abstract}

\begin{abstract}
Successful organisations are interested in achieving their business policy and goals, ideally with minimal financial expenses. Process Management approach is an effective way to meet the goal. There are two groups that are focused on the field of process standardization: Object Management Group and Workflow Management Coalition, each of them focuses on the process standardization from a different point of view. For solving complex issues it is effective to combine both approaches. That is the reason why this paper shows new Process Framework for Emergency Management which can describe precisely the process deployment in the area of emergency management taking into account its process oriented methodology and complex architecture. The correctness of the Process Framework is guaranteed by continuous verification, validation and optimization of emergency processes. Applicability of the solution is shown on a case study that simulates progress of an emergency situation in the real environment.
\end{abstract}

\section{INTRODUCTION}

Emergency Management (EM), sometimes called disaster management, is a discipline of dealing with and avoiding risks. It is a discipline that involves preparing for a disaster before it happens, disaster response, as well as supporting and rebuilding the society after a natural or a human-caused disaster occurs. In general, any EM is a continuous process in which all individuals, groups and communities manage hazards in an effort to avoid or ameliorate the impact of disasters resulting from the hazards (Mak et al. 1999; Rüppel and Wagenknecht 2007). Effective EM relies on thorough integration of emergency plans at all levels of government and non-government participants (Fiala and Ministr 2007).

Process Management (PM) is a field of combining management and technology focused on aligning organizations with the requirements and needs of clients (Kubíček et al. 2010; Řepa 2007). It is a complex management approach that promotes business effectiveness and efficiency while striving for innovation, flexibility, and integration with technology (Jain and McLean 2003). PM attempts to improve processes continuously. It could therefore be described as a process optimization process.

\section{Principles of the Emergency Management}

The organisation of the emergency management varies between the EU and US. However, there are still important commonalities. The nature of emergencies means that all levels of government (federal, state, regional or local) and all sectors of society are responsible for dealing with them (Diehl et al. 2006). There generally exists a Bottom $U p$ approach for requests for resources support that travel upward until appropriate resources are ensured and the incident stabilised. Each country has different legislation, procedures and obligatory documents to be followed within the EM process (Mak et al. 1999). There also exists no universal terminology within EM, not only internationally but even within the agencies across all government levels.

Coordination of Activities within the Emergency Management System is done at three levels, Tactical, Operational and Strategic (Rektořík 2004), and is corresponding with the generic conclusion defined by Orchestra (Klopfer and Kanellopoulos 2008).

The Strategic Level of the Rescue and Liquidation Works (RaLW) management is realised by standing or temporary coordinating authorities of the administration, region commissioners and Ministry of Interior - General Management of the Czech Republic Fire Rescue Corps. On the Operational Level, permanent coordination and cooperation within and between individual Integrated Rescue System (IRS) components takes place; this includes operational centres of the basic IRS components (Fire Rescue Corps, Police and Medical Rescue Service) and dispatching centres, standing services, and oversight centres of distributive and emergency services. The Operational and Informational Centre manages cooperation within the RaLW with IRS documentation. 
The Tactical Level includes activity coordination at the place of intervention and cooperation of IRS components. The intervention commander proclaims the appropriate Level of Alert, which predetermines the needs of the Forces and Means for the RaLW. The intervention commander organises the RaLW based on consultation with IRS component leaders; he or she also follows the document Model Action Activities of the IRS Components at the Common Intervention.

\section{Principles of Process Management}

Nowadays, there are two significant streams in the field of Process Management: i.e. Business Process Management presented by Object Management Group (OMG) and Workflow Management, which was originally created by Workflow Management Coalition (WfMC).

Business Process Management (BPM) is based on the observation that each product that a company gets to the market is the result of a number of performed activities (Weske 2007). Business processes are the key instruments to organize these activities and to improve the understanding of their interrelationships. Information technology deserves an important role in business process management, because more and more activities that a company performs are supported by it (Rüppel and Wagenknecht 2007). Business process activities can be performed manually or with a help of information systems (Sell and Braun 2009). BPM activities can in general be grouped into five categories (phases): Design, Modelling, Execution, Monitoring, and Optimization. They are related to each other and organized in a cyclical structure, showing their logical dependencies.

Workflow Management is built on architectural representation of a workflow management system called Workflow Reference Model, that is developed by WfMC. It identifies the most important system interfaces, covering broadly five areas of functionality between a workflow management system and its environment (Hollingsworth 2004).

Process Management and Business Processes are generally used to solve issues related to EM (Kubíček et al. 2010; Sell and Braun 2009; Vondrák 2008). The aim of this paper is to define Process Framework for Emergency Management, which allows more effective and complex process support for EM. During the deployment of processes there is also necessary to guarantee their overall quality (Jain and McLean 2003). Hence the paper describes methods to assure quality of processes, i.e. verification and validation (Sargent 2005). Continuous improvement of processes by process optimization is also very important (Rüppel and Wagenknecht 2007). Practical use of the Process framework, together with methods of process quality assurance is illustrated on the case study that describes an accident of a vehicle transporting dangerous goods.

\section{PROCESS FRAMEWORK FOR EMERGENCY MANAGEMENT}

Process Framework for EM is a new progressive view on process support of organizations in the private and public sector. It is created for the purpose of better understanding of issues that are connected with process deployment in the specific area of interest. The model covers not only process related issues, but also issues related to emergency management. Deep analysis of current solutions and approaches (Diehl et al. 2006; Klopfer and Kanellopoulos 2008; Sell and Braun, 2009) shows, that just this unifying view on process deployment is missing. Despite the fact, that the model is focused on the emergency area issues, the idea of creating a process framework is general and could be used also in other areas of expertise, where a complex and global view on the area of interest is needed. The general purpose of the model is given by two main views on the process issues, which are Methodology view and the global Architecture view.

\section{Methodology}

The first view is created by process oriented methodology. The main goal is to continuously improve process, which is the same idea as Deming cycle. This view is based on the Business Process Management lifecycle (Weske 2007). In order to talk about processoriented methodology, it is necessary to meet certain characteristics. The methodology consists of five basic phases, where every phase is further process decomposed. Namely there are these phases: Defining, Modelling, Configuration, Execution/Monitoring, and Optimization. The methodology contains user roles, which are necessary for correct progress of the process and the roles show responsibilities for the particular processes (Ludík and Ráček 2008). The roles are not just the ones focused on the ICT view of process deployment, as is the role of Analyst, Designer and Tester, but there are also roles for emergency management. Namely it is Intervention Commander, Operator of the Regional Operating Centre and last but not least specific Rescue Units. The next essential part of created methodology are individual work products, either input or output. Some of these artefacts are included into the process framework. There are primary phases like Defining, Modelling, Configuration and Monitoring. Executing and Optimization phases are described from a different point of view. Process execution is analysed from the view of tools that are needed for execution of modelled process instances. On the other hand the optimization phase is focused on techniques and options of process reengineering. The Fig. 1 shows on the left side the general process oriented methodology.

\section{Architecture}

The second part of the process model is created by process oriented architecture. It is based on WfMC 


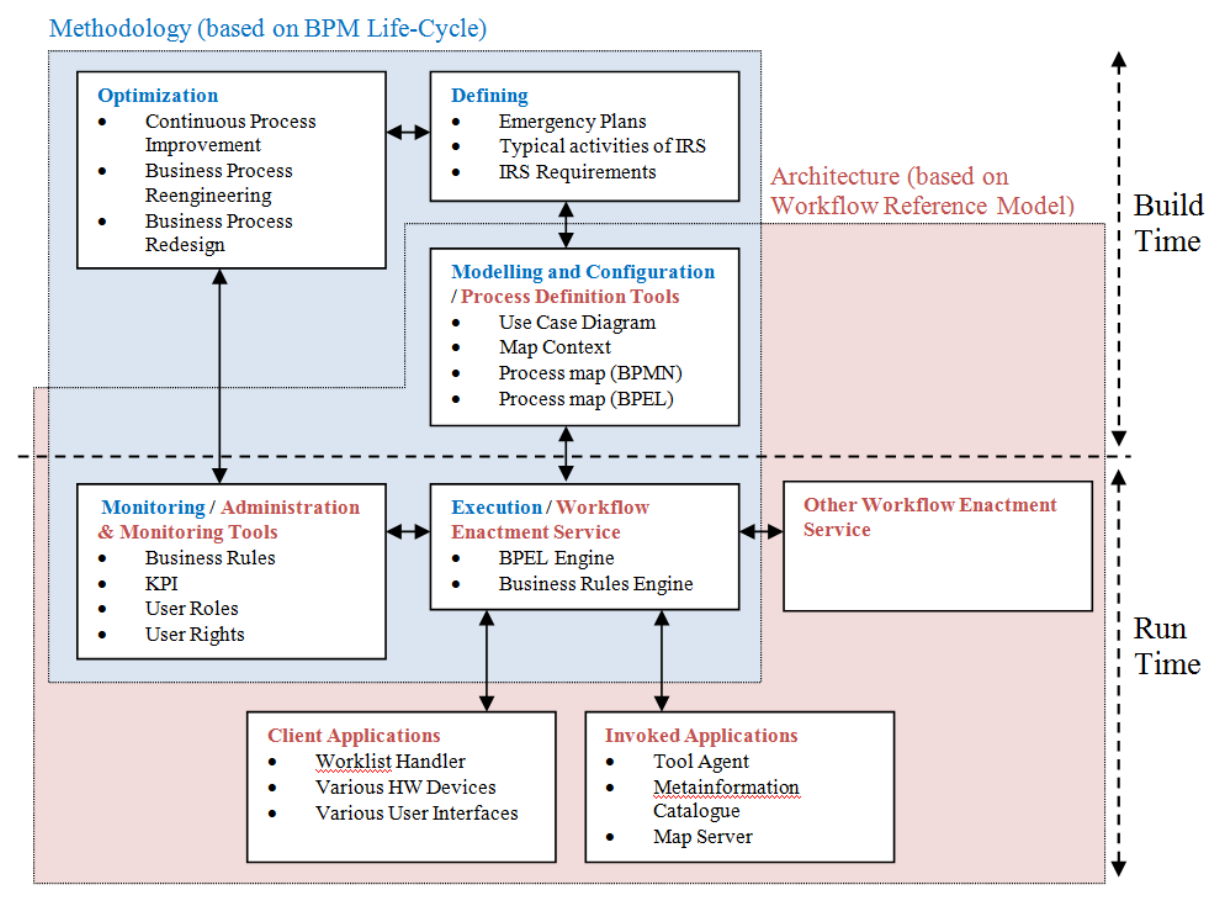

Figure 1: Process Framework for Emergency Management

principles and primarily focused on software tools required for process deployment into organisations. The major task is to define suitable interfaces for communication among individual components of architecture (Hollingsworth 2004). The architecture view is situated on the right side of the process framework. The main parts of the system are described from the view of software tools or hardware components use. Particularly that are parts like Workflow enchantment service, Client Application and Invoked application. The view is completed with issues of emergency management and because of this the model contains also components like Map Server, Metainformation Catalogue and various hardware devices or user interfaces that are necessary to manage specific crisis situations (Kozel 2007). The architecture view guarantees that outputs from individual phases of the methodology meet certain criteria and standards to use them in the next phase. The aim of the view is to create a global architecture that will serve as the essentials for modelled process instances deployment so that these instances could cooperate with other services and tools within clearly defined interfaces. Particular example of the architecture is shown on the Case Study (Fig. 4).

\section{Unifying View}

The Fig. 1 shows, that each of this two views covers another part of the spectrum needed for depth process analysis used in the emergency management. In some parts of the model there should be given more emphasis on the procedures and defined processes arising from the legislation and methodologies related to crisis management (Optimization and Defining). The process' architecture and clearly defined interfaces among the components are important to enable fast and effective communication among them (Client Applications, Invoked Applications, Other Workflow Enactment Service). The created process framework for emergency management contains also parts, where the methodology and architecture views overlap. In these parts, both views have to be taken into account to better understand the research issues. Especially it is very important in the Modelling phase of the methodology to determine how the modelling process will proceed and what are the specifics, keeping in mind that the resulting processes should be efficient, transparent, and also in the future simply sustainable ( software tools are also very important. It is necessary that the modelled processes could be easily readable for ICT users as well as for crisis managers. The main advantage of this approach is independence on particular software modelling tools. It is often necessary to use various software tools and combine them, whether for modelling, simulation or even possible optimization (Kubíček et al. 2010). It is obvious that the resulting interoperability between used tools plays a key role.

\section{QUALITY ASSURANCE OF BUSINESS PROCESS}

The Process Framework for Emergency Management provides guidance on how the processes can be effectively deployed in the field of emergency management. Application of the process framework shows that ensuring the overall quality of the modelled processes must be an integral part of the framework. For this purpose, the techniques of verification, validation, and optimization of the processes are used as well as case studies in the real environment. The verification 
process allows checking the output of the individual process framework phases and validation allows checking the completed automated processes in regard to customer's needs and requirements (Reijers 2003, Sargent 2005). At the same time, continuous improvement of the processes is extremely important because it provides organizations with a significant competitive advantage. Effective solving of emergency situations is critical and therefore it is required to verify the functionality of the automated processes in the case studies.

\section{Verification and Validation}

Verification and validation (Sargent 2005) enable continuous monitoring and testing of any software projects. Therefore, it is useful to apply them in the automation of emergency management processes. From the view of the process framework for emergency management it is appropriate to use verification and validation in the first three phases of Process Oriented Methodology. The phases are called: Defining, Modelling and Configuration (see Fig. 2).

The base of successful information system design is to understand customer's needs and requirements which are analysed in the Defining phase. This is a challenging process since the customers are not often able to specify clearly their needs. The result of this phase is a list of business requirements the new system has to meet. The list contains identified production, supporting and managerial processes. The identified processes are essential for the subsequent phases. It is necessary to verify whether the final list of requirements is in accordance with the relevant legislation and the organisation policies. Subsequently, it is appropriate to validate the requirements by the customer.

The following phase is modelling. Its aim is to model the identified processes to meet the costumer's demands. The output of this phase are complex process diagrams suitable for subsequent automation. The modelled processes need to be verified whether they meet the business requirements. Validation of this phase represents the customer's approval of the processes. Verification and validation is done by the process simulation techniques. These techniques detect possible defects or bottlenecks in the modelled processes and also illustrate the flow of business processes to the customer (Reijers 2003).

It is appropriate to use verification and validation techniques also in the Configuration phase. The output of this phase are automated processes that can be deployed to the Workflow Enactment Service. Testing and verification check the functionality of the automated process with regard to the process models. The customer verifies the functionality of created process-oriented system and this validation is critical for this phase. The validated system can be then deployed into business environment.

\section{Optimization}

To keep the competitive advantage it is not enough to deploy business processes but also to monitor and optimize them continuously. Process optimization is a discipline of adjusting a process so as to optimize some specified set of parameters without violating any constraints. The most common goals are minimizing costs and maximizing throughput and efficiency. This leads to a long-term sustainability. Continuous improvement is therefore crucial. Processes can be improved not only in the Optimization phase but also in the Defining, Modelling or Monitoring phase (Fig. 2).

The first process improvement is possible in the Defining phase. Customer describes the current processes ("as-is" processes) in the company to a business analyst. Some of the processes can be improved at this stage. Process automation gives space to a better process specification ("to-be" processes). It is not easy to change company processes, therefore it is necessary to get an external examination of the suggested changes by a member of the organization management who is not part of the project team.

The Modelling phase is the next stage where it is appropriate to optimize processes. Simulation is one of the techniques suitable for redesign support. The simulation of business processes helps to understand, analyse and design of processes. The designed and redesigned processes can be evaluated and compared during a simulation. The process simulation allows us to detect defects of proposed processes before they are deployed into real working environment (Vondrák et al. 2008). The optimized process is automated and deployed on a process engine.

Monitoring phase follows. Information about individual

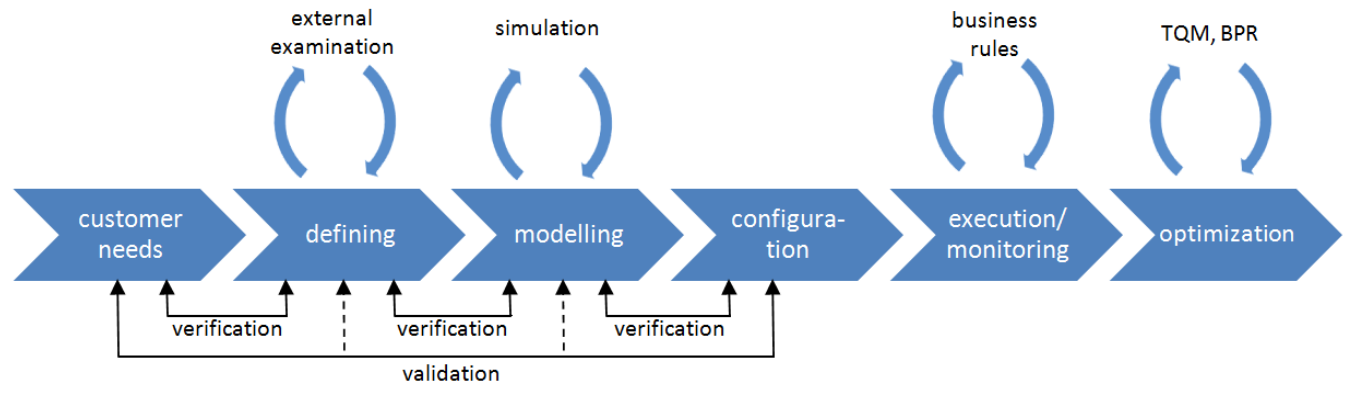

Figure 2: Quality Assurance of Business Process 
process instances is collected during this phase. It is possible to monitor progress and performance of individual process instances via the Key Performance Indicators (KPI). In this phase the process can be optimized by business rules which allow better reflection of the real world conditions (Mak et al. 1999). Another possibility to improve the running process is the modification of users' roles and rights.

The last phase of process framework is Optimization. This phase is suitable for comprehensive changes in business processes. These changes are supported by detailed analysis of data gathered during the monitoring of process instances. Statistical methods or process mining techniques are used for this purpose. Based on the obtained results, continuous or radical process improvement can be applied. Continuous improvement is represented by the Total Quality Management and radical improvement by the Business Process Reengineering (Davenport 1993).

\section{CASE STUDY}

This paper focuses on the tactical level of cooperation activity of the intervention commander and decisionmaking support during the organisation of intervention in the model situation called Accident of a vehicle transporting dangerous goods. The principal aim of this research is a cross-connection of process modelling and adaptive visualisation in the field of emergency management. The proposed solution is targeted on support of the intervention commander activities during the response phase of the accident of a vehicle with dangerous goods.

\section{Process Support of the Intervention Commander}

The event Accident of a vehicle transporting dangerous goods can be seen in complex view represented by the UML (Unified Modelling Language) Use Case Diagram. It is a basic view of the defining phase of process framework. The main purpose of the Use Case Diagram is to find and document modelled business requirements. Created diagram is verified and approved by user's validation. Diehl et al. (2006) used UML to model actors and relations between them with respect to 25 disaster management activities as specified in the Netherlands. They described and formalised selected measurements that might be needed if dangerous substances are released in different environmental conditions (air, water, soil, and surface). We are following similar procedure where each Use Case is based on analyses of the EM procedures in the Czech Republic. This model is also applicable for EM in other countries, but other actors and use cases would probably be administered. The border of the modelled system is defined by the Czech Fire and Rescue Act. By analysing the activities within the event, an actor list is created containing different roles that are assigned to persons or subjects that use the modelled system. Having understood the roles of the individual actors, it is possible to start to design the Use Cases. The external review of final Use Cases is necessary.

The Use Case is perceived as the specification of the activities sequence that the system or subsystem can execute through interacting with external actors. Each use case can be specified by a process map (Fiala and Ministr 2007) incorporating and defining the activity sequences in the particular directives (the modelling phase of process framework). A process is a set of activities arranged in parts. It creates in a repeatable way required output from one or more inputs. To illustrate a process map, the use case called Organisation of Intervention is elaborated. This directive controlled by the intervention commander consists of ten activities illustrated in the process map in Fig. 3. In this way, the process maps of organisation of intervention are created. Subsequently the modelled processes are simulated. The simulation reveals bottlenecks and inconsistences. Based on the results the processes are optimized.

During the configuration phase of process framework all modelled processes (process maps) are transformed to the Business Process Execution Language (BPEL), where the individual process activities are assigned to the required geoinformation. Within the activities of the intervention commander, it is possible to identify specific tasks that are more or less spatially dependent and thus require geoinformation support.

To determine what and how to visualise, it is necessary to decide what parameters will determine the context in which geographic information will be used. In order to simplify the application of process framework for emergency management, the following parameters were selected to define the context: USER - member of Fire Rescue Corps, ACTION - organising of intervention, SITUATION - accident of a vehicle with dangerous goods, DEVICE - TabletPC. Broadly, ACTION and SITUATION determine the knowledge that is needed

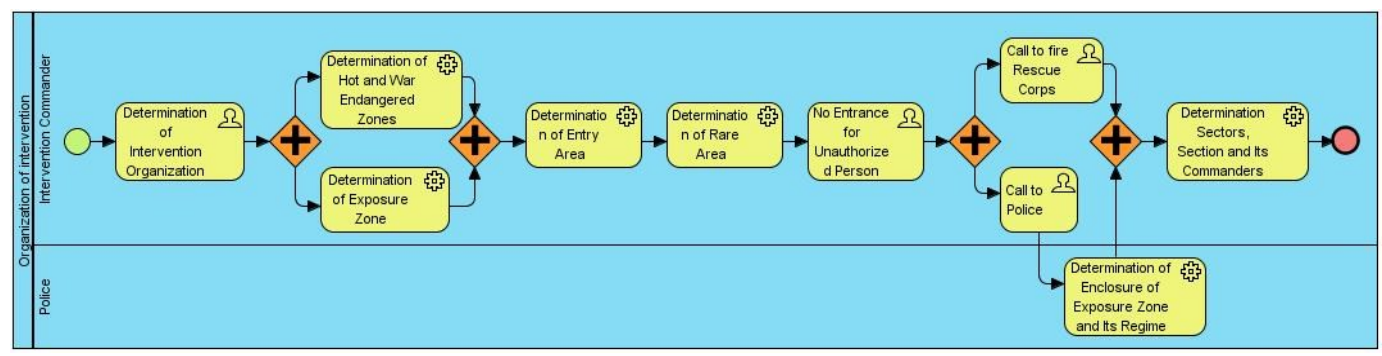

Figure 3: The process map of Organisation of Intervention. 
for decision-making and thus what to visualise. USER and DEVICE specify how to visualise this data, i.e. set the visualisation criteria.

The process formalisation in the BPEL form specifies which geoinformation are supposed to be used and finds an appropriate way to visualize them. The so-called context specific map is used for this purpose and is visualised over the background of a topographic base. This BASETOPO is a set of topographic features that can be reused in other contexts. The BASETOPO is defined at several scales - in the application of process framework, the use of BASETOPO in large-to-middle scale is expected.

\section{Terrain Case Studies}

The case study was led by the researchers of the research plan Dynamic Geovisualisation in Crises Management and represents business processes deployment and their execution and monitoring according to the process framework. The case study was focused on monitoring processes and testing Contextual Web Map Service (CWMS) and also technologies for vehicle tracking in a real situation (Friedmannová 2010; Kozel 2007), namely during a response phase of a crisis since the main scope of the CWMS (and CWMS client) is to provide support at the time when a disaster is happening.

During the case study the CWMS client was deployed into the complex system that provided support for a fast response to a crisis situation (Palas 2010). The system is showed in Fig. 4.

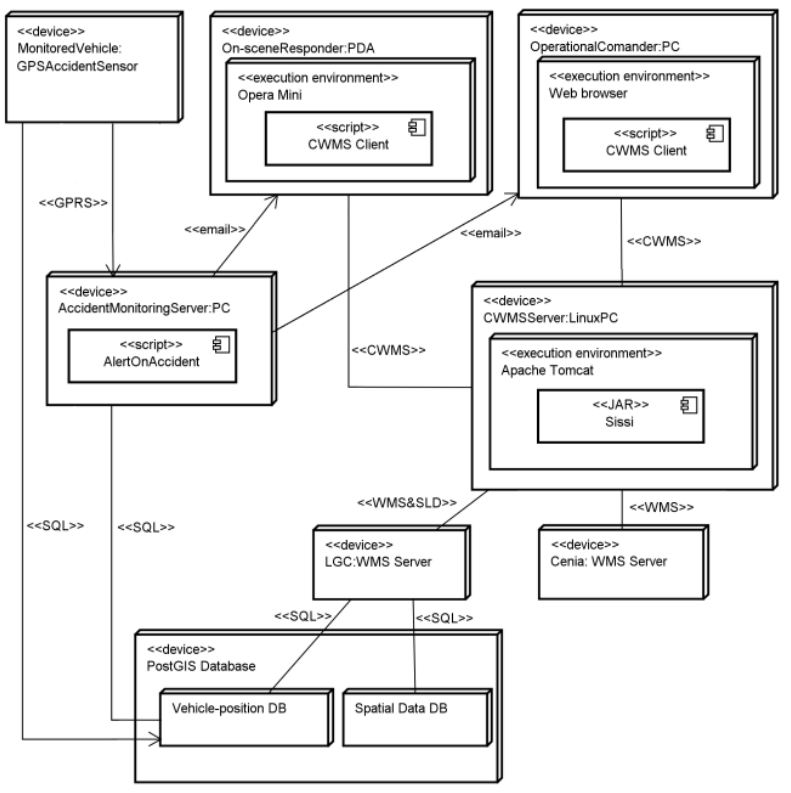

Figure 4: Deployment of the CWMS Client

Each vehicle transporting dangerous substances carries a GPS receiver with an accident sensor and a GPRS transmitter. All the time the vehicle is moving, it sends its position in regular intervals via GPRS to the database that contains positions of all vehicles. When an accident happens, a signal alerting the accident is sent to the server which handles incoming accident signals. A simple PHP script constantly runs on the server. When a signal of a new accident is received, the script obtains the current position of the crashed vehicle from the vehicle-position database.

Furthermore, the script generates an URL of the CWMS client where location and context of the accident in parameters are encoded. Such a CWMS client's URL is immediately sent to an operational centre of IRS and consequently to on-scene responders for the accident via email.

Having received an email informing about the accident, a man in charge clicks the link and the CWMS client opens up in a web browser, showing the accident in the proper context. Operational commanders in operational centres of IRS are likely to use PCs while on-scene responders are likely to use PDAs.

Regardless of the device, the CWMS client requests deserved map for the current situation from the MapServer via CWMS. Map-Server immediately requests required spatial data from Laboratory on Geoinformatics and Cartography (LGC) WMS Server or Cenia WMS Server and builds the deserved contextual map which is sent to the CWMS client afterwards.

Spatial data for contextual maps including positions of tracked vehicles are provided by LGC WMS Server, which obtains them from the PostGIS database via SQL. Cenia WMS Server provides just aerial photos which might be required for several contextual maps. Based on the terrain case study results the complex optimization of the processes according to the process framework is available.

\section{CONCLUSIONS}

The paper introduces a completely new perspective for the process analysis and deployment. It integrates the current views of organizations as OMG and WfMC and designs new and innovative Process Framework for EM. A model showed the issue of processes in two perspectives, both in terms of process-oriented methodology and in terms of process architecture. The designed model covers the issues of crisis management, which makes the benefits of bridging the two different views even more transparent. The created model is a supplement with specifics for crisis management and is therefore accessible not only to users of IT but also in crisis management.

The functionality of the Process Framework is guaranteed by continuous verification, validation and optimization of emergency processes. Applicability of the solution is also guaranteed by the terrain case study that simulates the progress of typical activities of IRS that describe the Accident of a vehicle transporting dangerous goods in the real environment.

To complete the Process Framework, it is necessary to create and describe a process-oriented methodology, which will define actions for the support of processes in 
crisis management. The second part consists of hardware and software analysis. It is also necessary to define interfaces between components. The use of standards in this area considerably eases the demands for interoperability. Functionality and efficiency of established methodology and architecture will be validated by case studies. Up to this point the proposed Process Framework will be considered final and it can be deployed in practice, not only on issues related to crisis management, but also to other specific areas.

\section{ACKNOWLEDGEMENTS}

The contribution is part of the research plan no. MSM0021622418 and the research project no. FRVS/1035/2011, both supported by the Czech Ministry of Education, Youth and Sports.

\section{REFERENCES}

Davenport, T., 1993. "Process Innovation: Reengineering Work Through IT. " Harvard. Boston.

Diehl, S., Neuvel, J., Zlatanova, S., et al., 2006. "Investigation of user requirements in the emergency response sector: the Dutch case." In Proceedings of the Second Gi4DM, Goa, India.

Fiala, J., Ministr, J., 2007. “The Model of Process Framework in Czech Public Government." In Proceedings of the 26th International Conference on Organizational Science Development - Creative Organization. University of Maribor. Portorož.

Friedmannová, L., 2010. "Designing Map Keys for Crisis Management on the Regional Operational and Infromational Centre Level: Monitoring Transport of Dangerous Goods via Contextual Visualization." In Geographic Information and Cartography for Risk and Crisis Management. Springer-Verlag. Berlin Heidelberg. ISBN 9783642034411.

Hollingsworth, D., 2004. "The Workflow Reference Model: 10 Years On". In The Workflow Handbook 2004.

Jain, S., McLean, Ch., 2003. "Simulation for emergency response: a framework for modeling and simulation for emergency response." In Proceedings of the 35th conference on Winter simulation: driving innovation. Winter Simulation Conference.

Klopfer, M., Kanellopoulos, I., 2008. "Orchestra, an open service architecture for risk management." The ORCHESTRA Consorcium. ISBN 9783000242847.

Kozel, J., 2007. "Open Contextual Cartographic Visualization." In Proceedings of the 5th Geographic Information Days - Young Reseachers Forum. Münster : IfGI prints.

Kubíček, P., et al., 2010. "Process Support and Adaptive Geovisualisation in Emergency Management." In Geographic Information and Cartography for Risk and Crisis Management - Towards Better Solutions. SpringerVerlag. Berlin Heidelberg. ISBN 9783642034411.

Ludík, T., Ráček, J. 2008. "Process Analysis of Dynamic GeoVisualization in Environmental Crisis Management." In Environmental Informatics and Industry Ecology. 22. International Conference on Informatics for Environmental Protection. EnviroInfo 2008. Shaker Verlag. Aachen. ISBN 9783832273132.
Mak, H., Mallard, A., Bui, T., et al., 1999. Building online crisis management support using workflow systems. In Decision Support Systems 25. Elsevier.

Palas, J., 2010. "Dynamic Visualization of Spatial Data for Emergency Management." Master thesis. Masaryk University. Brno.

Reijers, H. 2003. "Design and Control of Workflow Process: Business Process Management for the Service Industry." Springer-Verlag. Berlin Heidelberg. ISSN 03029743. ISBN 3540011862.

Rektořík, J., 2004. "Crisis management in public sectors." Ekopress. Praha. ISBN 8086119831. (in Czech)

Řepa, V., 2007. "Business Processes, Process Management and Modelling." Grada. Praha. ISBN 9788024722528. (in Czech)

Rüppel, U., Wagenknecht, A., 2007. Improving emergency management by formal dynamic process-modelling. In 24th Conference on Information Technology in Construction.

Sargent, R., 2005. "Verification and validation of simulation models." In Proceedings of the 2005 Winter Simulation Conference. ISBN 0780395190.

Sell, Ch., Braun, I., 2009. "Using a Workflow Management System to Manage Emergency Plans." In Proceedings of the 6th International ISCRAM Conference. Gothenburg, Sweden. ISBN 9789163347153.

Vondrák, I., Martinovič, J., Kožuszník, J. et al. 2008. "Floreon - System For Flood Prediction." In Proceedings of the 22nd European Conference on Modelling and Simulation. Nottingham Trent University. Nottingham. ISBN: 9780955301858.

Weske, M., 2007. "Business Process Management, Concepts, Languages, Architectures." Springer-Verlag. Berlin Heidelberg. ISBN 9783540735212.

\section{AUTHOR BIOGRAPHIES}

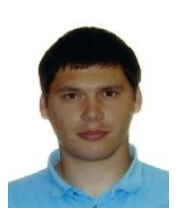

TOMÁŠ LUDÍK is Ph.D. student at the Faculty of Informatics, Masaryk University in Brno. He has been working in the research of process management, emergency management and software engineering since 2006. His e-mail address is: xludik2@fi.muni.cz and his Web-page can be found at http://is.muni.cz/osoba/72692? lang=en.

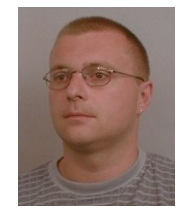

JAROSLAV RÁČEK is senior researcher and assistant professor of Masaryk Univerzity in Brno. He has been working in the research of workflow, process analysis and software modelling since 1996. His e-mail address is: racekefi.muni.cz and his Web-page can be found at http://is.muni.cz/ osoba/3444 ? lang=en.

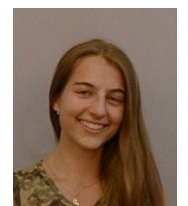

LUCIE PEKÁRKOVÁ is Ph.D. student at the Faculty of Informatics, Masaryk University in Brno. She has been working in the research of process management and e-learning since 2007. Her e-mail address is: pekarkovaefi.muni.cz and her Webpage can be found at http://is.muni.cz/osoba/ 60555? lang=en. 